\title{
Improving the Efficiency Learning Through Adapt the Teaching Style to the Learning Style
}

\author{
Costică $\operatorname{Lupu}^{1 *}$
}

\section{ABSTRACT}

Education in recent decades has focused on the debate over adolescent affection which has a great influence on the mind. Many studies have shown that teachers adapt the teaching to student learning style can improve learning efficiency. To do this study we focus on a sample of 124 students aged 14 to 16 years, including 84 girls and 40 boys (from five classes IX from different profiles) at the National Pedagogical College " Stefan cel Mare "of Bacau, 5 mentors teachers and 15 students participated in educational practice conducted by the Department of teacher Training at the "Vasile Alecsandri" University of Bacau .

The paper starts from the following assumption: if adolescent affection has a great influence on his intellect, then learning is strongly influenced by the emotional state that is mastered.

In the present research, the research hypothesis is considering the implementation of steps to the observation of the behaviour in high school and its subsequent impact on the adolescent behaviour.

The hypothesis arising from the research objectives: - establishing strategy analysis approaches for achieving positive affective education in high school; - create a systematic observations of how education can be found affective steps a day program teaching practice;- analysis, data processing and presentation of observational research methods to realize affective education by infusional approach.

The result shows that it takes a positive affective approach to education in high school and affective state of students is of paramount importance in expressing interpersonal cognitive, communicative, cooperative or competition within the school group they belong. Therefore, depends in particular on how the individual is impressed, moved, affected by what is taught, what you perceive this to affect its relations with others, its role busy group and school reality.

Keywords: Observational Research, Mental Phenomena, Emotionality, Learning, Intellect.

\footnotetext{
1 "Vasile Alecsandri" University of Bacău, România, Faculty of Sciences, Department of Mathematics-Informatics and Education Sciences, România

*Responding Author

(C) 2016 I C Lupu; licensee IJIP. This is an Open Access Research distributed under the terms of the Creative Commons Attribution License (http://creativecommons.org/licenses/by/2.0), which permits unrestricted use, distribution, and reproduction in any Medium, provided the original work is properly cited.
} 


\section{Improving the Efficiency Learning Through Adapt the Teaching Style to The Learning Style}

Although distinct from one another, cognitive and emotional processes are closely interconnected. When emotional conflict generated by clashing emotions, feelings and passions is united with cognitive conflict, caused by the clashing of ideas and concepts, intellectual activity is enhanced. If emotionality decreases, reaching the state of indifference, the individual's ability to solve new problems also decreases.

These emotions, located at the emotional-intellectual level, are generated by competitive actions that occur in the school and social sphere. Most often than not, these trigger anxiety, frustrations, guilt. In school activity, there also occur envy, admiration, modesty, hypocrisy and suspicion. The school environment comprises, in fact, multiple stimulating and also traumatising factors caused by teachers, school syllabi, marks, students.

By looking into this topic we aim to answer two questions. Is shyness present at teenagers and to what extent do the emotional transformations undergone by teenagers impact their learning process? Along with the beginning of school, a child starts a new form of activity, undertaking the status of student that triggers relevant transformations at the level of the psychological processes and phenomena that regulate and stimulate learning.

The teenager's education revolves around and focuses on the idea of good and bad in relation to everything that the young person experiences. His entire development is strongly influenced by the very numerous communication messages, what is broadcasted on TV, newspapers, books and radio shows, as well as information on the Internet. The emotional experiences from the lessons on various educational disciplines achieve an increasingly complex nature.

\section{Problem of Research}

The research aims to identify the presence of shyness at teenagers and the factors impacting the learning process during adolescence. Conducting education with the aim of building positive emotionality at high-school students contributes to building proper behaviour towards learning.

\section{The research hypotheses}

The research relies on the following hypotheses:

- If the student has a high level of shyness, then his intellectual ability and emotional state are dominated by fear of failure.

- If the teenager's emotionality has particular influence on his intellect, then the learning process is strongly marked by the emotional state that he experiences.

\section{The research objectives}

Along with the beginning of school, a child starts a new form of activity, undertaking the status of student that triggers relevant transformations at the level of the psychological processes and phenomena that regulate and stimulate learning. 
The hypothesis has generated the research objectives that guide and gradate the research activity:

- Establishing the strategy for analysing the processes for achieving emotional-positive education in high-school education;

- Conducting a systematic observation on the extent to which emotional education may be identified during the schedule of one-day teaching practice;

- The analysis, processing and presentation of the data from the observational research on how emotional education is achieved through the infusion approach.

\section{THEORETICAL ASPECTS}

\section{Emotionality}

In dealing with reality, man actualizes certain needs, interests, aspirations and ideals, internal stimuli of the human condition that are called motivational structures. Between motivation and the surrounding reality there occur confrontations and clashes whose effects are the very emotional processes.

The mental processes that reflect the relations between subject and object in the form of emotions are called emotional processes. Within emotional processes, the most relevant aspect is not the object itself but the meaning attributed by the object to the subject. That is why, one and the same object generates different emotional states at different people.

Emotionality does not have specialized operations and tools like in the case of thought and imagination, but it is expressed as a tension of the organism, resulting in attraction-repulsion, search-oscillation. Close interactions also exist between emotionality and motivation. Emotional processes are regarded as representing active reasons in progress, whereas reasons are nothing else but crystallized emotional processes (Dumitriu Gh., 2004, p.78).

\section{The properties of emotional processes}

The polarity of emotional processes consists of their tendency to gravitate between the positive and negative poles, occurring as a result of meeting or not meeting the differentiated needs and aspirations of individuals. Polarity may be of the following nature: pleasurable or unpleasant, stenic or astenic (states that enable or demobilize activity), tense or relaxed.

The intensity of emotional processes indicates the depth of the experienced emotion at a given moment. It relies on the emotional value of the object in relation to the subjects' needs and emotional capacity. Enhancing the intensity of emotional experiences is achieved not by repeating the stimuli but by changing the meanings of the emotional value of the object or person with whom we interact, (Lupu C., 2014).

The duration of emotional processes consists of their length in time, irrespective of whether the person or object that caused them are present or not. A feeling may last one year or a lifetime, an 


\section{Improving the Efficiency Learning Through Adapt the Teaching Style to The Learning Style}

emotion may last several seconds or several hours, the fear and horror related to an accident may persist even after the danger is gone, love persists even if the loved person is gone.

The mobility of emotional processes is expressed as the accelerated transition within the same emotional state (from one stage to another), or as the transition from one emotional experience to another. Mobility should be distinguished from the fluctuation of emotional states that also imply a transition from one mood to another, however without any reason, without being required by some objective or subjective demand, as in the case of mobility.

The expressiveness of affective processes consists in their ability to become externalized. The outer manifestation is achieved by means of certain exterior signs that are called emotional expressions (mimicry, panto-mimicry, vegetative changes, change of voice etc.). Emotional expressions have individual as well as social meaning, (Lupu C., 2013).

\section{The classification of emotional processes}

Primary emotional processes have a primitive, natural-spontaneous nature, are weakly organized and tend to escape conscious control. The main forms are: the affective tone of cognitive processes (they emotionally accompany every act of knowledge), emotional experiences of organic origin (generated by the good or bad functioning of internal organs), emotions (primitive emotional forms, impulsive, strong, very intense and violent, shortly lived).

Complex emotional processes enjoy a higher degree of awareness and intellectualization, are more easily controllable and overlap learning to a higher extent. The main forms are: current emotions (shortly lived, active, intense, caused by distinct traits of objects, namely: joy, sadness, pleasure, disgust), higher emotions (connected more to an activity that the individual conducts than to objects and imply evaluations), emotional moods (diffuse feelings with variable intensity and relative duration that may turn into character traits), (Cristea S., 2003).

Higher emotional processes are characterized by a high degree of organization and value relation and are located at the level of personality. The main forms are:

- Feelings are intense emotional experiences, have a long duration, are relatively stable, characteristic of humans and socially-historically conditioned. The association of feelings is not haphazard, but follows a series of rules and laws. The French psychologist Theodule Ribot asserted the existence of a logic of feelings. Feelings may be: intellectual (curiosity, wonder, doubt, love for truth); - aesthetic (admiration, ecstasy); moral (patriotism, duty); the feelings of the Ego (self-love, high or low self-esteem, anxiety and hope); - human social and psycho-social feelings (vanity, dignity, sociability).

- Passions are feelings with a certain orientation, intensity, very high levels of stability and generality that engage the entire personality. They may fall into two great categories: lucid or noble (social orientation for truth, justice, progress) and blind (related to the ego 
- possessive passions: avarice, fanaticism; related to the other - jealousy, ambition; related to the world - passion for gambling), (Birch A., 2000).

\section{The relation between emotionality and intellect at children during the learning process}

The intellect is a system of relationships, activities and mental processes (intelligence, reason, memory, imagination, language) where thought is the central mental process that guides, leads and exploits all the other mental processes and functions. Intellectual efficiency depends especially on the individual's emotional state. Emotionality is characterized by affects, emotions, passions, moods and ensures the energetic support for the learning activity, (Şchiopu U. 1979, p 127).

In order to reach a maximum level of efficiency in the learning process, the subject needs to have, besides motivation, intelligence, purpose and proper emotional processes, the corresponding energy that may guide him towards knowledge and satisfaction. Without the emotional connection between what the exterior activity imposes (teacher, group, colleagues) and the students' internal conditions, the structuring of a constructive attitude and favourable, motivational relations in the socio-educational process is not possible.

\section{The relationship between emotionality and intellect as a factor involved in the process of adaptation}

There are two ways of learning: individual and group. They are both efficient, but they need different contexts to materialize.

In order for the individual learning process to yield high levels of performance, there should occur a conflict in the student's conscience, interests, intellectual ways and personal emotional state. On the one hand, the clash between the cognitive and emotional processes has to reach the optimum level in order to remove indifference or mental discomfort and trigger the student's motivation and ability. On the other hand, collective learning imposes the establishing of compatibility between the subjects' cognitive and emotional processes, in order to obtain maximum results. Therefore, the contextual factors, the relationships with the others, with the activity, situations and tasks have a relevant value in achieving performance in school learning.

\section{METHODOLOGY OF RESEARCH}

\section{General Background of Research}

To experiment the formulated hypothesis, there were applied active, relatively objective methods that enable the observation, recording and measuring of the subjects' reactions to different external stimuli, as well as a complementary system of methods that may enable the investigation of the phenomenon in terms of its general manifestations (within the group of students) and specific manifestations (in individual cases). The ones used most often were: psychological and pedagogical tests; - questionnaires (applied individually). 


\section{Improving the Efficiency Learning Through Adapt the Teaching Style to The Learning Style}

\section{Research on emotional manifestation}

Research has shown that the concern for oneself represents the introductory stage of what we call self-conscience. The second convergent tendency is that of inferiority, manifested as shyness that is no longer caused by fear of strangers, but the need to protect and defend psychic intimacy from the interventions of others who could regard it as childish or may find it amusing.

For example, the case of a student, R. Lorena who, although an intelligent teenager with a high learning motivation, blushes and feels embarrassed when being heard by the teacher, becoming incapable of expressing the knowledge she has acquired during learning in a fluent manner and during the lessons, when she has something to say, she does it in a very discomfited way, stirring collective amusement. This occurs due to her shyness that springs from the fear of expressing herself in front of a large number of people, even if these are her classmates.

We should note the fact that in the written tests, she obtains optimum marks, therefore she cannot be placed in the category of mediocre students. The solution to Lorena's problem is achieving self-confidence and this may be done by means of internal factors (courage, will, attitude) as well as external factors (classmates, teachers, family, society).

J. Piaget has highlighted the parallelism between the evolution of logic and will that occur at the same time to give more coherence to thought and action. Constantly pursuing goals from different activities, organizing the effort made to conform to moral rules, the psychic instrumentation of making decisions generates more behavioural coherence, stability, unity and continuity (Piaget J., 1972).

For example, the case of a girl, S. Andreea who, although both her parents work abroad while she lives with her grandmother, manifests a particular interest towards school, having very good results. The cause of her motivation for school is her awareness of the need to learn in order to be able to aspire to a promising future. If during the younger grades Andreea got good school results because her mother imposed rules and a learning schedule on her now, when her mother can no longer watch her closely, Andreea finds her own motivation as a consequence of the habit of learning, of standing out among her classmates and in front of her teachers, of feeling herself useful and capable. Thus, Andreea is a lucid teenager, willing to assert herself, these qualities helping her to achieve performance in the learning process.

\section{Sample of Research}

To conduct the research and demonstrate the role of the relation between emotionality and intellect as a factor involved in the process of adaptation, the study was conducted on a sample of

124 students aged 14-16 years of age, 84 girls and 40 boys (from five $9^{\text {th }}$-grade classes with different specializations) from the "Ștefan cel Mare" National Pedagogical College of Bacău, with the participation of 5 teachers mentors and 15 students from the Pre- and In-Service 
Teacher Training Department from "Vasile Alecsandri” University of Bacău, during their teaching practice stage.

\section{Instrument and Procedures}

Besides these research methods, the 15 students also resorted to essential methods during the pedagogical observation stage from their teaching practice that they conduct as part of their preservice teacher training within the Pre- and In-Service Teacher Training Department from "Vasile Alecsandri" University of Bacău: observation, conversation, analysis of evaluation samples, synthetic and analytical tables, graphical representations, surveys on the students' preferences and interests related to learning.

\section{Data Analysis}

The research began at the start of the 2014-2015 school years and was completed in March 2015. The group of students investigated during the research represent social groups formed in the $9^{\text {th }}$ grade. The students' level of psychic development is heterogeneous. Most of the students come from families with preoccupations for forming, teaching and educating their children, maintaining a constant relationship with the school.

\section{RESULTS OF RESEARCH}

Analysing the data obtained during the 20 observed lessons, we were able to create the tables below in order to establish the percentage to which there were identified processes of behaviour observation in situations that involve emotional experiences from the total of observations, as well as the degree of manifestation, their frequency according to the applied criterion and their graphical illustration:

Table 1. Processes observed and the number of lessons.

\begin{tabular}{|l|l|}
\hline Lessons during which there were identified processes of behaviour observation & 15 \\
\hline Lessons during which there were not identified processes of behaviour observation & 5 \\
\hline Total & $\mathbf{2 0}$ \\
\hline
\end{tabular}

Fig. 1. The percentage of the identification of processes of behaviour observation

\section{Number of lessons}

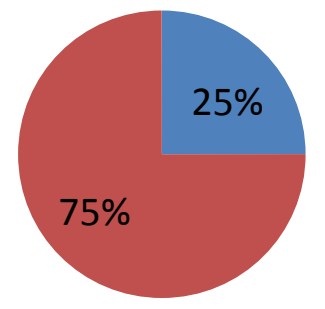

Lack of infusion processes

Infusion processes 
Improving the Efficiency Learning Through Adapt the Teaching Style to The Learning Style

Table 3. The degree of manifestation and the frequency according to the applied criterion

\begin{tabular}{|c|c|c|}
\hline The applied criterion & $\begin{array}{l}\text { Degree of } \\
\text { manifestation }\end{array}$ & Frequency \\
\hline \multirow{5}{*}{ Infusion through contents } & Very high degree & 7 \\
\hline & High degree & 4 \\
\hline & Average degree & 2 \\
\hline & Low degree & 2 \\
\hline & Very low degree & 2 \\
\hline \multirow{5}{*}{ Infusion through images/ materials from nature } & Very high degree & 5 \\
\hline & High degree & 4 \\
\hline & Average degree & 0 \\
\hline & Low degree & 0 \\
\hline & Very low degree & 0 \\
\hline \multirow{5}{*}{ Infusion through actions } & Very high degree & 0 \\
\hline & High degree & 3 \\
\hline & Average degree & 3 \\
\hline & Low degree & 0 \\
\hline & Very low degree & 0 \\
\hline $\begin{array}{l}\begin{array}{l}\text { Lessons observed that have no behaviour related } \\
\text { message }\end{array}\end{array}$ & & 5 \\
\hline
\end{tabular}

Analysing the table above, we may find the weight of each analysed criterion (the infusion of the processes of observing intellectual ability and emotional state through contents, images/ materials from nature), according to their degree of manifestation (very high degree, high degree, average degree, low degree, very low degree), as shown in the graphs below:

Fig. 2. The degree of infusion of the processes of building intellectual ability and emotional state through contents

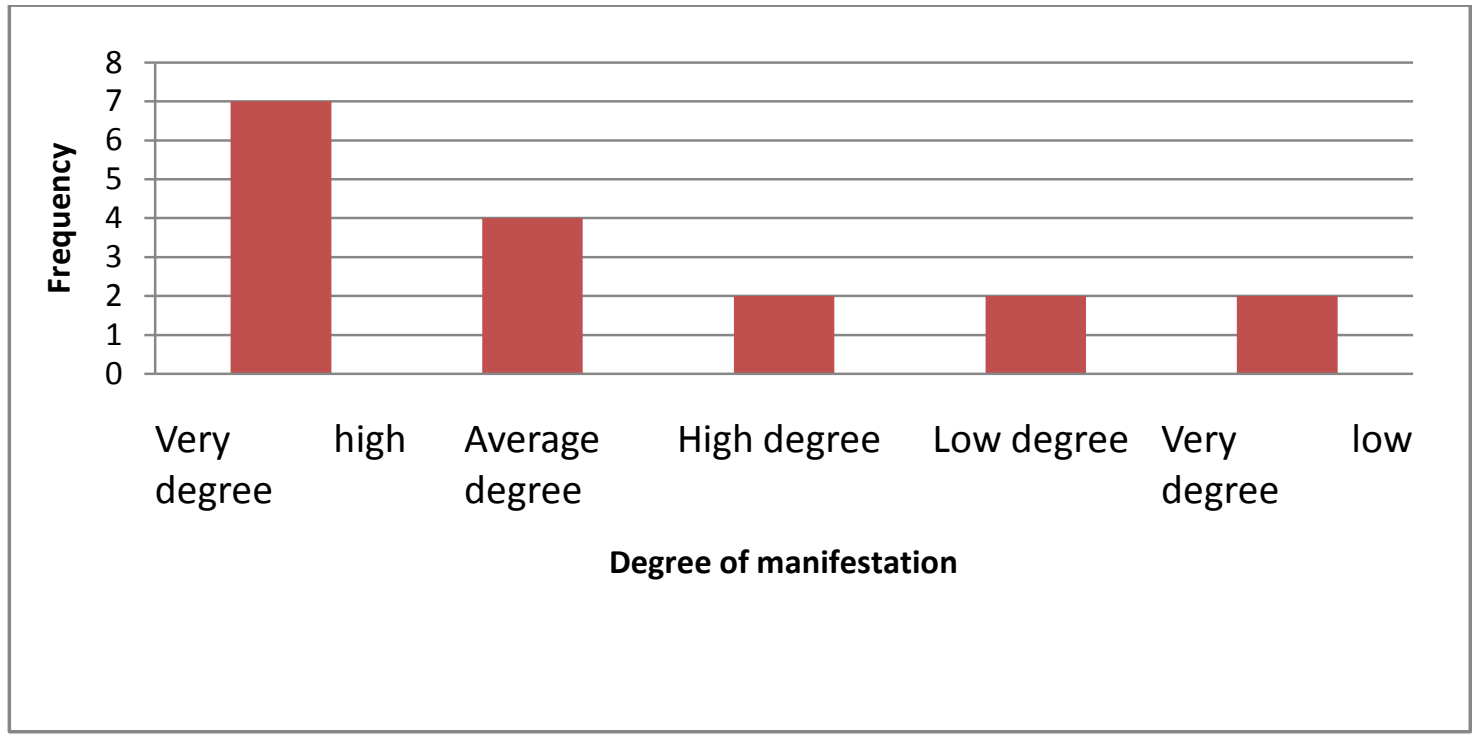


Fig. 3. The degree of infusion of the processes of building intellectual ability and emotional state through images of/materials from nature

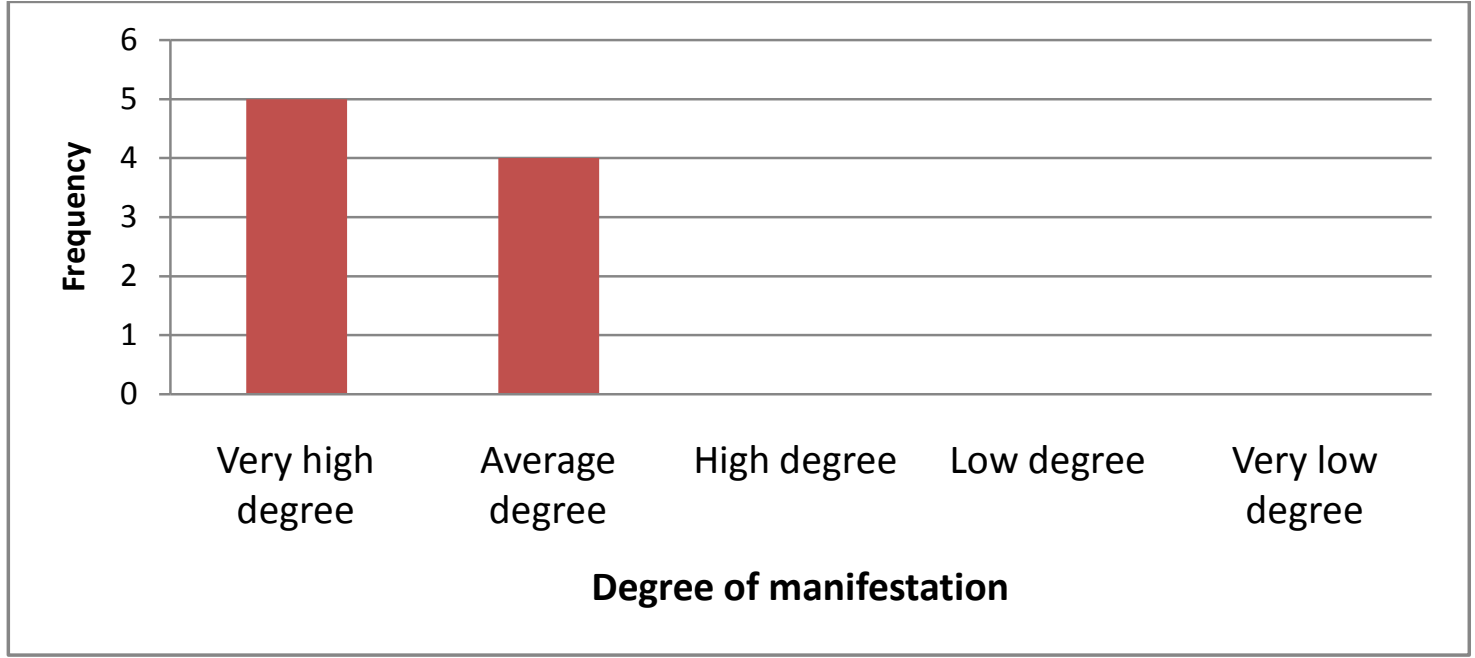

Fig. 4. The degree of infusion of the processes of building intellectual ability and emotional state through practical actions

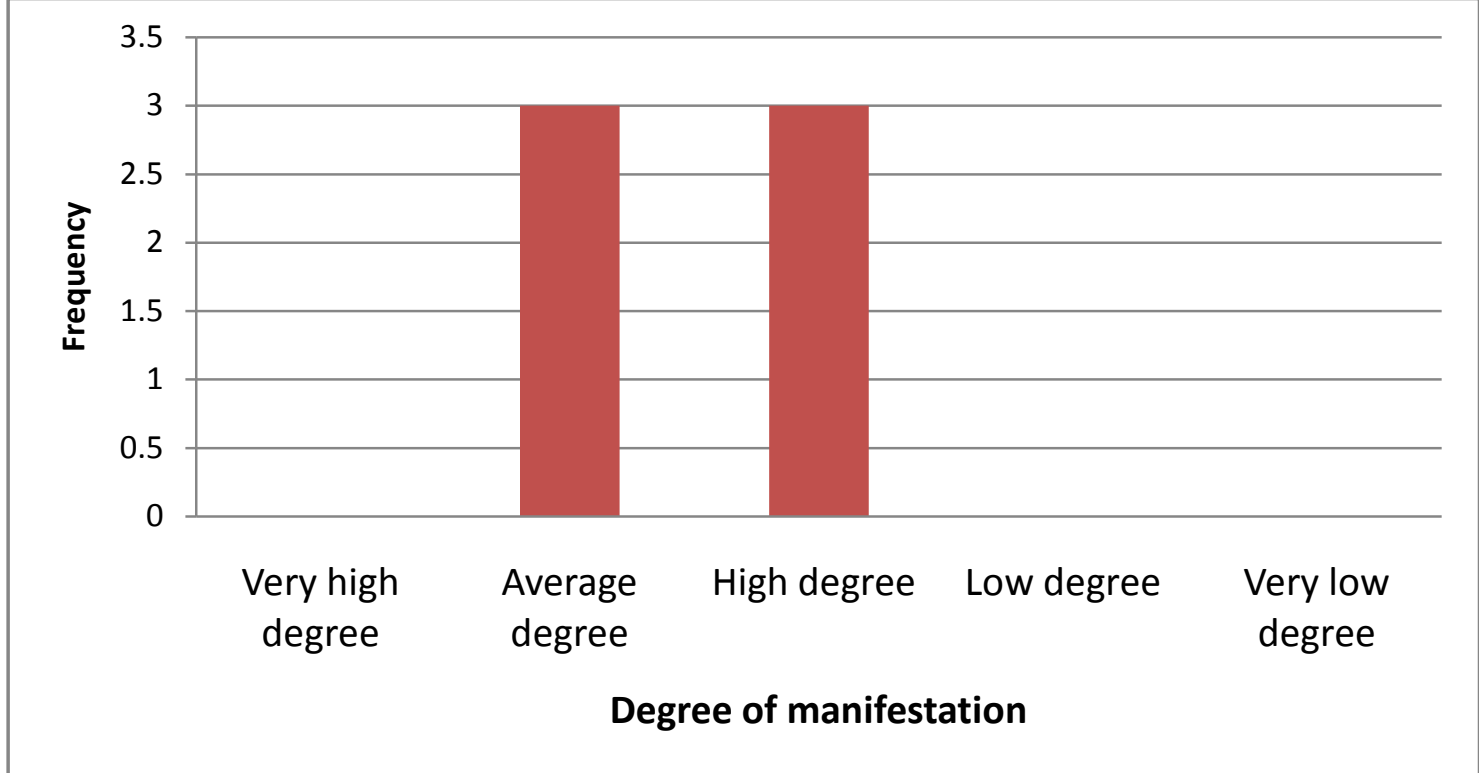

It is interesting to note the fact that there are processes of building intellectual ability and emotional states occurring simultaneously during several stages of a lesson, as well as the fact that a stage of a lesson may contain messages infused both through contents and images/ materials from nature or practical actions.

Comparing the percentages according to the criteria of evaluation and the percentages according to curricular areas (only for those where there was conducted the observation of the processes of intellectual education and emotional state), we may draw the following tables: 
Table 4. Percentage of the infusion processes in the learning activity of the cognitive and emotional processes of the subjects according to the applied criteria

\begin{tabular}{|l|l|}
\hline Applied criterion & Frequency \\
\hline Contents & 17 \\
\hline Images/ materials from nature & 9 \\
\hline Practical actions & 6 \\
\hline Total & 32 \\
\hline
\end{tabular}

Fig. 5. The percentage of the infusion processes in the learning activity in relation to the cognitive and emotional processes according to the evaluated criteria

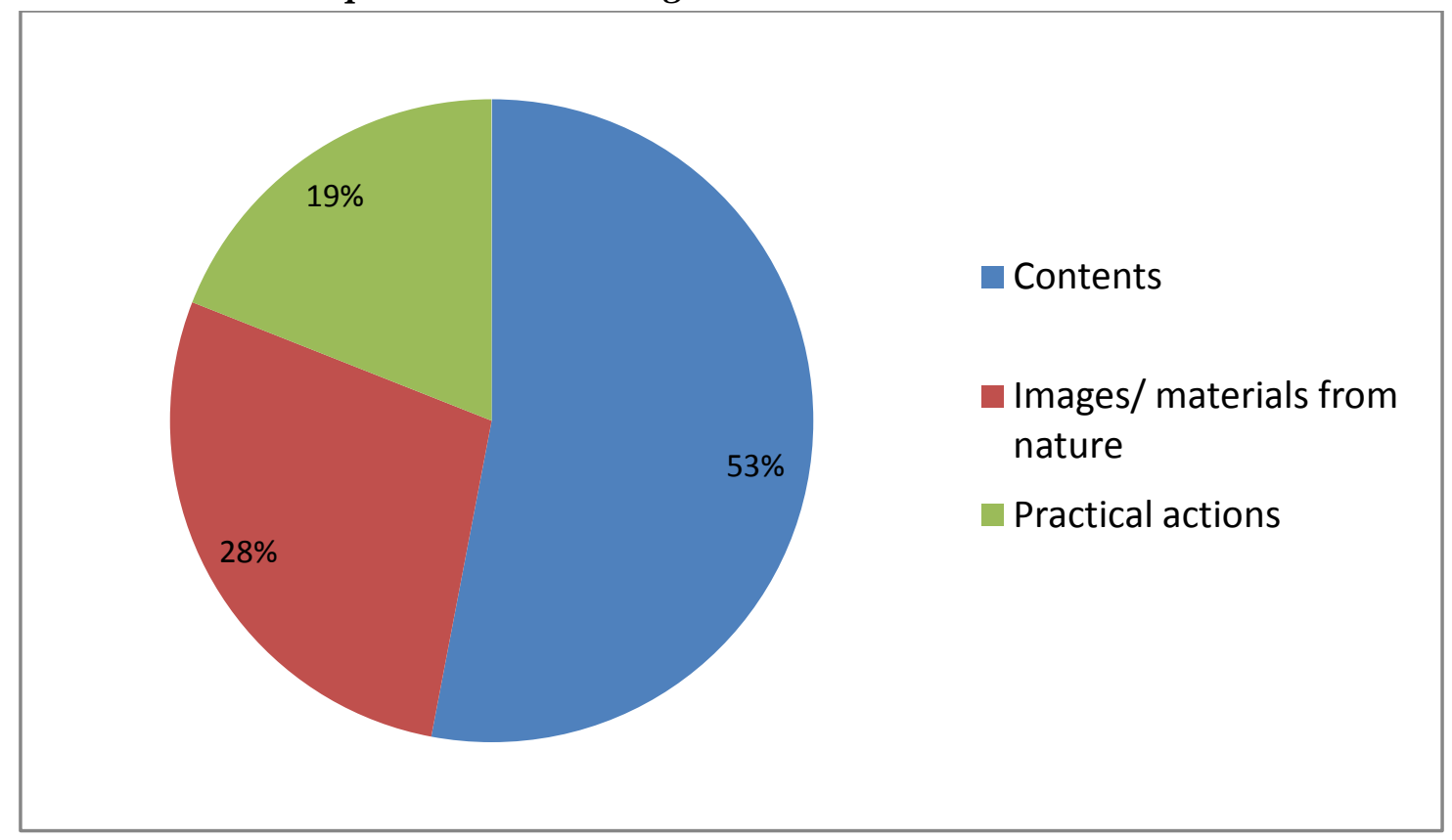

Analysing the tables above we may observe the obviously greater percentage of the infusion of the processes of ecological education through contents compared to the infusion through images/ materials from nature and actions, as well as of the area of Mathematics and Sciences compared to the other areas observed, as shown in the graphs below:

Table 5. Percentages of the infusion processes in the learning activity of the subjects' cognitive and emotional processes according to the criterion of curricular areas

\begin{tabular}{|l|l|}
\hline Curricular area & Frequency \\
\hline Mathematics and Sciences & 6 \\
\hline Language and Communication & 3 \\
\hline Arts & 1 \\
\hline Technologies & 5 \\
\hline Total & 15 \\
\hline
\end{tabular}


Fig. 6. The percentage of the infusion processes in the learning activity in relation to the cognitive and emotional processes according to curricular areas

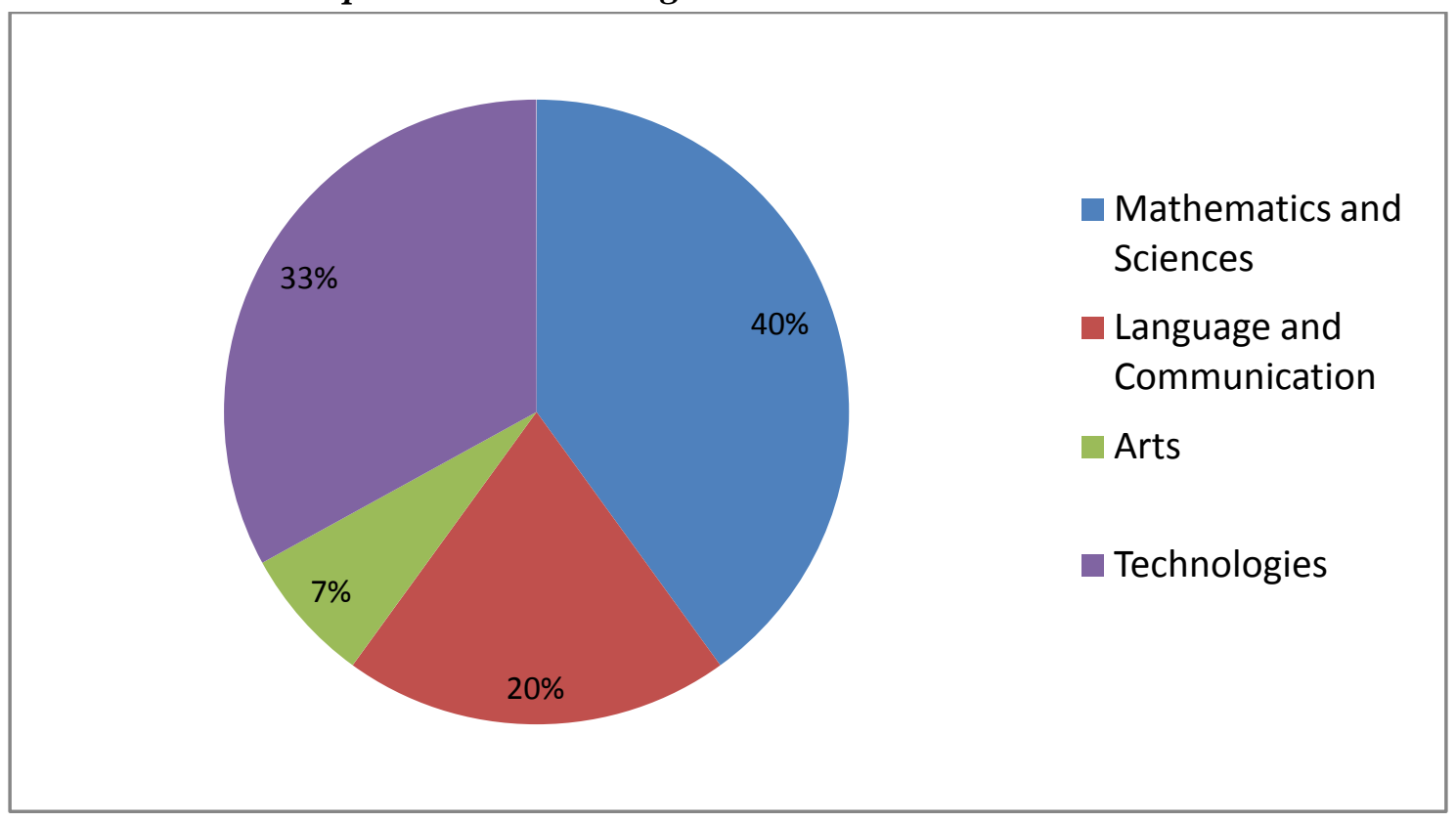

\section{CONCLUSIONS}

As a result of the observations conducted during the 20 lessons and of the comparison, analysis and graphic representation of the data we may formulate the following conclusions:

1. from the total of 20 observed lessons, there occur infusion processes of education in the learning activity strongly affected by the emotional state in 15 lessons (75\%), whereas for the remaining 5 lessons (25\%) there were proposals to achieve it;

2. most of the processes were approached by means of the contents (53\%), images/ materials from nature being used only in $28 \%$ of them and practical actions only in $19 \%$;

3. most of the processes occur within the area of Mathematics and Sciences (40\%), followed by Language and Communication (33\%), Technologies (20\%) and Arts (7\%) (we should mention the fact that only lessons belonging to these curricular areas were observed due to the teaching-practice day that was established to be Friday);

Therefore, emotional processes have a particular impact upon the intellect, making it oscillate between progress and regress according to emotions.

Observing the behaviour in situations that contain emotional experiences involved a sample of 120 teenagers, aged 15-17, students in the first year of high-school from "Ion Ghica” Economic College of Bacău and yielded the following results:

$80 \%$ of the students have emotional experiences normal for their age (positive events have an organisational effect, the experiences being intense but stable, not dominating the teenagers' 
behaviour, the negative events have the effect of producing chaos, the experiences also being intense but fluctuating and not dominant for the teenagers), whereas the answers given by $20 \%$ of the students show that these have an abnormal behaviour both during positive and negative events in their life.

\section{REFERENCES}

Birch A. (2000). Developmental Psychology, (trans.), Technical Publishing House, Bucharest. Buzdugan T. (1999). Psychology in the interest of all, Didactic and Pedagogic, Bucharest.

Cristea S. (2003). Dictionary of pedagogy, Group Editorial Letter / Letter International Bucharest.

Dumitriu Gh. (2004). Cognitive system and component development, Didactic and Pedagogic, Bucharest.

Hayes N. \& Orrell S. (1998). Introduction to Psychology, All Publishing, Bucharest.

Lupu C. (2008). Pedagogical paradigm of school discipline didactics, Didactic and Pedagogical. Bucharest.

Lupu C . (2013). Epistemological and Psychological Fundamentals of the Didactics of Science, Social and Behavioral Sciences Volume 92, 490-494. Reserved from http://www.sciencedirect.com/science/article/pii/S1877042813028371

Lupu C. (2014). The Model Object-product-cognitive Operation Through Mathematical Education, Social and Behavioral Sciences proceed, Volume 163, Pages 132-141. http://www.sciencedirect.com/science/article/pii/S187704281406399X

Piaget J. (1972). Psychology and Pedagogy (trans.), Didactic and Pedagogic, Bucharest.

Ribot Théodule-Armand, (1896). La psychologie des sentiments, Paris.

Şchiopu U. (1979). The crisis of originality in adolescents, Didactic and Pedagogic, Bucharest. 